\title{
Ciência e ética em publicação em Psiquiatria: o papel dos conflitos de interesse
}

\author{
Science and ethics in publications in Psychiatry: the role \\ of conflicts of interest
}

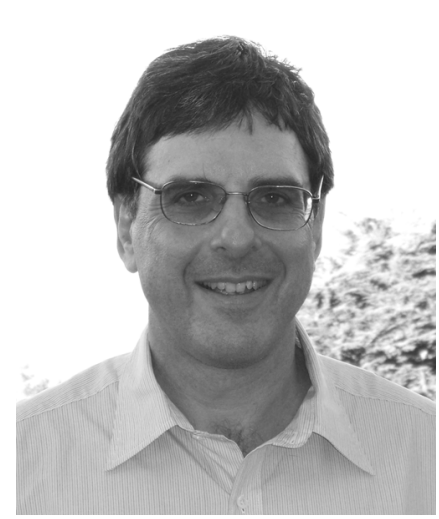

\author{
Mauro V. Mendlowicz* \\ * Professor adjunto, Departamento de Psiquiatria e Saúde Mental, Universidade Federal Fluminense \\ (UFF), Niterói, RJ. Editor associado, Jornal Brasileiro de Psiquiatria. \\ Relatório apresentado no Fórum de Publicações - Ciência e Ética em Publicações em Psiquiatria, XXVI \\ Congresso Brasileiro de Psiquiatria, Brasília, realizado em outubro de 2008.
}

Deu no New York Times! Uma comissão parlamentar de inquérito norte-americana, liderada pelo senador Charles E. Grassley, está investigando não apenas as relações financeiras de pesquisadores de renome, como Alan Schatzberg, Charles Nemeroff e Joseph Biederman, com a indústria farmacêutica, mas a própria estrutura de financiamento da American Psychiatric Association (APA). Em 2006, a indústria farmacêutica foi responsável por cerca de $30 \%$ do orçamento da APA, principalmente através do patrocínio de periódicos científicos, congressos e simpósios. Em uma carta à APA, o congressista manifestou sua preocupação quanto a esse estado de coisas, afirmando que "afinal, havia entendido como o dinheiro da indústria farmacêutica pode moldar a prática de organizações não lucrativas que pretendem ser independentes em seus pontos de vista e ações". O Dr. Steven S. Sharfstein, ex-presidente da APA, reconheceu a gravidade da situação e observou: "A cada nova revelação, nossa credibilidade com os pacientes fica comprometida e nós temos que protegê-la a todo custo".

Ao contrário do que possa parecer à primeira vista, o nó da questão não reside na existência pura e simples de vínculos econômicos entre pesquisadores, instituições médicas e a indústria farmacêutica. Essa associação emergiu e se fortaleceu de forma gradual ao longo das últimas décadas, em parte como resultado de novas leis, como o Bayh-Dole Act (de 1980), que permitiram a universidades, pequenas empresas e instituições sem fins lucrativos se beneficiarem da propriedade de suas invenções, em detrimento do governo federal, e facilitou a transferência das tecnologias por elas desenvolvidas para os setores privado e público. Também contribuiu para o estreitamento das relações entre academia e indústria a crescente capacidade e disposição desta última em financiar pesquisas. Nos EUA, a verba de pesquisa das companhias farmacêuticas aumentou de US\$1,5 bilhão, em 1980, para US\$ 22 bilhões, em 2001 (um incremento de 1367\%), dos quais US\$ 6 bilhões foram investidos em clinical drug trials ${ }^{1}$. Essas parcerias se tornaram, hoje em dia, um elemento de grande importância e, por vezes, indispensável para o progresso científico em muitos campos.

$\mathrm{O}$ verdadeiro problema diz respeito à forma inadequada com que os conflitos de interesse que emergiram de tais relacionamentos vêm sendo administrados por determinadas pessoas e instituições. Conflitos de interesse (CDI) são conjuntos de condições no qual o julgamento profissional referente a um interesse primário (como, por exemplo, o bem-estar dos pacientes ou a validade de uma pesquisa) tende a ser indevidamente influenciado por interesses secundários (como, por exemplo, prestígio pessoal ou ganhos econômicos) $)^{2}$. Os conflitos de interesse podem se manifestar a nível pessoal - no caso dos médicos e dos pesquisadores - ou institucional - no caso das universidades, instituições de pesquisa e revistas científicas.

Há três estratégias básicas para lidar com o conflito de interesse, cada qual com suas vantagens e limitações. A primeira delas é a declaração da existência de conflitos de interesse. Editores de periódicos científicos exigem que os autores dos manuscritos a eles submetidos declarem seus CDI. Palestrantes devem fazer o mesmo em relação à sua 
audiência. Da mesma forma, pesquisadores devem levar seus CDI ao conhecimento das agências de fomento ou dos comitês de ética em pesquisa. Embora a declaração seja considerada por alguns como "a regra de ouro para os CDI", ela padece de algumas limitações. Em primeiro lugar, a declaração de CDI é um ato voluntário baseado num sistema de honra que não inclui maiores salvaguardas. Nos rumorosos casos citados acima, os pesquisadores deixaram de declarar as impressionantes quantias que receberam durante anos da indústria farmacêutica (seja como pagamento por serviços de consultoria ou à guisa de verbas de pesquisa) às suas universidades, que, por sua vez, se revelaram singularmente incompetentes para detectar e sanar essas irregularidades.

Mais ainda, pesquisas sugerem que a declaração de CDI pode não ser tão efetiva, em termos de correção do julgamento do público-alvo, quanto o senso comum faz crer. De um modo geral, as pessoas tendem a subestimar o papel das influências situacionais e a superestimar a influência do caráter e dos valores sobre o comportamento de terceiros. Em conseqüência, têm dificuldades em julgar a verdadeira extensão da influência que os CDI exercem sobre o julgamento de indivíduos que reconhecem estar em situação de conflito de interesse. A declaração de CDI pode ter o efeito paradoxal de aumentar a confiança do público na fonte de informações, reduzindo a capacidade daquele de corrigir o seu julgamento quanto à possível falta de objetividade e de isenção da mesma. Por outro lado, suspeita-se que algumas fontes de informação tendam a transmitir mais informações com viés após terem feito a declaração de CDI. Assim, por exemplo, uma vez revelada publicamente a existência de CDI, alguns autores e conferencistas podem se sentir moralmente autorizados a transmitir informações marcadas por vieses ou mesmo para superenfatizar suas conclusões e recomendações, de modo a descontar os efeitos da sua declaração. Cain et al. ${ }^{3}$ alertaram que a revelação dos CDI poderia, paradoxalmente, causar mais mal do que bem, dada a incapacidade das pessoas em lidar com informações cuja qualidade está sabidamente comprometida por conflitos de interesse.

A segunda estratégia é a proibição (ou eliminação) de CDI. Trata-se de um procedimento drástico que deve ser utilizado de forma criteriosa, sendo aplicável principalmente a casos graves de CDI econômicos (por exemplo, quando o indivíduo é acionista ou administrador de companhia farmacêutica ou fabricante de equipamentos médicos ou ainda tem a opção de compra de ações da mesma). Pesquisadores em tais situações deveriam se abster totalmente de participar de atividades críticas, como regulamentação e supervisão de pesquisas (por exemplo, participação em comitês de ética em pesquisa) ou de atuar como reviewer de manuscritos ou de solicitações de verbas de pesquisa (grants).

As limitações da proibição de CDI ficam patentes quando se analisa a experiência de alguns periódicos científicos com essa estratégia. Nos anos noventa, os editores do New England Journal of Medicine decidiram que a mera declaração de existência de CDI por parte dos autores de manuscritos poderia, em certos casos, não ser suficiente. Havia a preocupação que editoriais e artigos de revisão, por representarem seleções e interpretações pessoais do(s) autor(es) a partir da literatura científica existente, pudessem se mostrar particularmente vulneráveis a manipulações com finalidades comerciais. Em conseqüência, o New England Journal of Medicine passou a exigir que os autores de editoriais e de revisões não tivessem nenhum interesse financeiro na companhia que fabrica o produto discutido no artigo ou em seus concorrentes comerciais. A conseqüência inesperada dessa política bem-intencionada foi que, num período de dois anos, os editores do New England Journal of Medicine não conseguiram publicar senão uma única revisão de farmacoterapia envolvendo uma nova medicação. Os editores concluíram que, se os periódicos científicos de alto nível deixassem de publicar artigos de revisão escritos pelos autores mais qualificados, seus leitores ficariam inteiramente à mercê das companhias farmacêuticas para obterem as informações que necessitam ${ }^{4}$.

Frente a essa situação, os editores se viram forçados a abandonar sua política de proibição de CDI e adotar uma de gestão de CDI, a terceira e última estratégia existente: o New England Journal of Medicine passou a exigir que os autores de editoriais e de revisões não tivessem nenhum interesse financeiro significativo na companhia que fabrica o produto discutido no artigo ou em seus concorrentes comerciais. A inclusão da palavra significativo representa um reconhecimento implícito de que nem todos os vínculos financeiros são do mesmo calibre: enquanto considera-se improvável que a percepção de honorários das companhias farmacêuticas para dar palestras ocasionais venha a comprometer a independência e a isenção de um pesquisador, possuir a opção de compra de ações da mesma companhia seria eticamente inaceitável. Os editores do New England Journal of Medicine determinaram que US\$ 10 mil por ano seria a quantia máxima que um autor poderia receber de uma companhia farmacêutica, para que o interesse financeiro não fosse considerado significativo. Segundo a revista, essas diretrizes deveriam ser consideradas mais como princípios gerais do que regras fixas e imutáveis. Caberia aos editores da revista ponderarem os fatos sabidos sobre cada autor em potencial e tomarem as decisões que, acreditem eles, venham a trazer a melhor informação médica e científica para a revista ${ }^{4}$. 
A gestão de CDI é uma estratégia intermediária entre a relativa passividade da declaração de CDI e o purismo da proibição de CDI, embora não exclua o uso moderado desta última. Como vimos, um dos procedimentos básicos para a gestão de CDI consiste em identificar áreas críticas na produção e disseminação do conhecimento que mereçam proteção mais ativa do que a mera declaração de $\mathrm{CDI}$ e das quais pesquisadores com CDI potencialmente sérios devam ser preliminarmente afastados (por exemplo, recrutamento e obtenção do livre consentimento informado de participantes de clinical drug trials). Outro procedimento fundamental é a criação de comitês encarregados de rever o projeto de pesquisa de forma a garantir que não esteja eticamente comprometido. $\mathrm{O}$ processo de monitoração por parte do comitê de revisão deve contemplar "pontos críticos de controle", tais como: solicitações de verbas de pesquisa, submissão dos projetos aos comitês de ética em pesquisa, encaminhamento de relatórios a agências específicas (por exemplo, Food and Drug Administration) e publicações. Em tese, a gestão de CDI seria a estratégia ideal para lidar com os mesmos. Contudo, o número e a complexidade dos julgamentos envolvidos no processo de pesquisa nos tempos atuais exigiriam a constituição de uma máquina burocrática imensa que terminaria por engessar e sufocar o progresso científico. Considerase, portanto, improvável que os planos de gestão de CDI consigam prevenir totalmente a ocorrência de influências indesejáveis sobre os projetos de pesquisa.

Os conflitos de interesse permeiam quase todas as atividades humanas, inclusive a Ciência e a Medicina. Não há nada intrinsecamente anti-ético nas interações entre médicos, pesquisadores e a indústria, como não há nada inerentemente anti-ético quando um médico, pesquisador ou autor se descobre em uma situação de conflitos de interesse. A situação se torna problemática, contudo, quando ocorre a recusa de se reconhecer a existência de um conflito de interesse e se perde a oportunidade de resolvê-lo de forma satisfatória. O reconhecimento da existência de um conflito de interesse não corresponde à admissão de uma grave falha moral, mas representa uma avaliação realística do impacto potencial de interesses secundários. Confiar na integridade pessoal do médico e do pesquisador é absolutamente indispensável, entretanto não tem se revelado suficiente. Nenhuma, dentre as três principais estratégias atualmente disponíveis para lidar com CDI, parece satisfazer as desejáveis metas gêmeas da efetividade e da exeqüibilidade. A eliminação do CDI só parece ser aplicável aos casos envolvendo conflitos particularmente graves. A pesquisa psicológica recente colocou em dúvida a efetividade da declaração de CDI. Os complexos julgamentos envolvidos na pesquisa científica também parecem comprometer a efetividade dos planos de gestão de CDI. Uma abordagem flexível, adaptada às especificidades de cada situação, parece ser a conduta mais adequada frente às limitações das estratégias atualmente disponíveis.

Neste momento crítico em que alguns dos mais importantes pesquisadores e instituições psiquiátricas do mundo se revelaram incompetentes para administrar autonomamente seus CDI e, em conseqüência, o governo americano dá mostras de sua intenção de tomar a si esta função, é importante, mais do que nunca, que médicos, pesquisadores, editores de periódicos científicos e dirigentes institucionais estejam conscientes da importância de reconhecer precocemente seus CDI e que estejam familiarizados com as estratégias para lidar com eles.

\section{Referências}

1. Bodenheimer T. Uneasy alliance-clinical investigators and the pharmaceutical industry. N Engl J Med. 2000;342(20):1539-44.

2. Thompson DF. Understanding financial conflicts of interest. New Engl J Med. 1993;329(8):573-6.

3. Cain D, Loewenstein G, Moore D. The shortcomings of disclosure as a solution to conflicts of interest. In: Moore D, Cain D, Loewenstein G, Bazerman M, eds. Conflicts of interest: cand solutions in business, law, medicine, and public policy. New York: Cambridge University; 2005. p. 104-25.

4. Drazen J, Curfman G. Financial associations of authors. New Engl J Med. 2002;346(24):1901-2. 